\title{
Características estruturais do dossel de pastagens de capim-tanzânia mantidas sob três períodos de descanso com ovinos ${ }^{1}$
}

\section{Rodrigo Gregório da Silva², Magno José Duarte Cândido ${ }^{3}$, José Neuman Miranda Neiva ${ }^{4}$, Raimundo Nonato Braga Lôbo ${ }^{5}$, Divan Soares da Silva ${ }^{6}$}

\author{
${ }^{1}$ Parte da dissertação apresentada pelo primeiro autor como parte das exigências para a obtenção do grau de Mestre em Zootecnia no curso \\ de Mestrado em Zootecnia. Financiada pelo Banco do Nordeste. \\ 2 Faculdade Tecnológica CENTEC, Quixeramobim - CE. \\ ${ }^{3}$ Departamento de Zootecnia, Universidade Federal do Ceará. \\ ${ }^{4}$ Curso de Zootecnia, Universidade Federal do Tocantins. \\ ${ }^{5}$ Embrapa-Caprinos. \\ ${ }^{6}$ Universidade Federal da Paraíba.
}

RESUMO - Avaliou-se a estrutura do dossel em pastagem de Panicum maximum Jacq. cv. Tanzânia sob lotação rotativa com três períodos de descanso (PD), definidos de acordo com o tempo para a expansão de 1,5; 2,5 e 3,5 novas folhas por perfilhos ao longo dos ciclos de pastejo. Estimaram-se as produções de massa seca de lâmina verde (MSLV), colmo verde (MSCV), de forragem morta (MSFM) e de altura; as relações folha-colmo (F/C), material vivo-morto (MV/MM), no pré e pós-pastejo; as taxas de crescimento da cultura (TCC) e acúmulo de forragem (TAC), a densidade populacional de perfilhos (DPP) no pré-pastejo e o índice de área foliar residual (IAFr). Com o avançar dos ciclos de pastejo, as diferenças entre os três períodos de descanso para as variáveis altura, produção de MSLV e MSCV foram acentuadas, especialmente no final do período experimental. A quantidade de MSFM se manteve semelhante dentro de cada período de descanso ao longo dos ciclos de pastejo, porém, na média dos ciclos de pastejo, o período de descanso para expansão de 3,5 folhas foi superior. As relações F/C e MV/MM foram maiores nos piquetes mantidos sob os períodos de descanso para expansão de 1,5 e 2,5 folhas em relação ao de 3,5 folhas. Os maiores valores para TCC e TAC foram obtidos nos piquetes mantidos sob períodos de descanso para expansão de 2,5 e 3,5 folhas. A densidade de perfilhos foi maior nos piquetes mantidos sob período de descanso para expansão de 2,5 folhas em relação ao de 3,5 folhas. O período de descanso para expansão de folhas é o mais indicado para o manejo de pastagens de Panicum maximum cv. Tanzânia com ovinos, pois permite a obtenção de boas produções de folhas em relação aos colmos sem comprometer a densidade populacional de perfilhos. Entretanto, com esse período de descanso, verifica-se aumento da altura pós-pastejo, a qual deve ser controlada por meio de roçada mecânica ou manual.

Palavras-chave: ciclo de pastejo, morfologia de gramínea, ovinos, relação folha/colmo

\section{Canopy structural traits of tanzaniagrass pastures under three resting periods and grazed by sheep}

ABSTRACT - The canopy structural traits of tanzaniagrass (Panicum maximum Jacq. cv Tanzania) pastures under three resting periods (PDs), defined as the time to complete the expansion of 1.5, 2.5, and 3.5 new leaves per tiller, along several grazing cycles (CPs), were evaluated. The following response variables were evaluated: green leaf dry matter mass (MSLV), green stem dry matter mass (MSCV), dead forage dry mass (MSFM), canopy height, leaf/stem and live/dead material ratios at pre- and post- grazing, crop growth rate (TCC) and net accumulation rate (TAC), tiller populational density (DPP) before grazing, and the residual leaf area index (IAFr). Differences among the PDs were acentuated toward the end of the experimental period for the variables canopy height, MSLV, and MSCV. The MSFM was not modified during the CPs in each PDs, but, averaging all the cycles, the 3.5 leaves PD pastures showed higher MSFM than the others. The leaf/stem and the live/dead material ratios were higher at the 1.5 and 2.5 leaves PDs pastures, than at the 3.5 leaves PD pasture. The 2.5 and 3.5 leaves PD pastures showed the highest TCC and TAC values. The DPP was higher at the 2.5 leaves PD pastures, than at the 3.5 leaves PD pasture. The PD for the expansion of 2.5 leaves per tiller is the better indication to manage Panicum maximum cv. Tanzânia pastures with sheep, because it promotes higher proportion of leaves, without decreasing the tiller population density. However, this management decision leads to higher post-grazing stubble height, which may need to be controled by manual or mechanical mowing.

Key Words: grazing cycle, grass morphology, leaf/stem ratio, sheep 


\section{Introdução}

A massa de forragem produzida em uma pastagem é resultado da combinação da produção de lâminas foliares, hastes e do número de perfilhos em determinada área (Hodgson, 1990), ao passo que o seu valor nutritivo depende de suas proporções e mesmo da idade fisiológica (Cândido et al., 2005c).

A espécie, o ambiente em que está inserida e o manejo da sua desfolha definem o comportamento da pastagem quanto ao número de plantas por área ou densidade populacional de perfilhos (DPP). O contínuo surgimento de perfilhos e sua capacidade de manutenção ao longo do tempo caracterizam a persistência da pastagem durante os ciclos de pastejo. Langer (1963) mencionou que o tempo de vida do perfilho e a sua taxa de renovação são aspectos importantes para a persistência da comunidade de plantas na pastagem.

A altura do dossel depende do tempo de rebrotação da gramínea e das adaptações morfológicas ao longo desse período (Cândido et al., 2005a,b). Segundo Uebele (2002), entre as variáveis relacionadas ao manejo da pastagem, a freqüência de desfolhação é a que mais atua na manutenção da altura do dossel da pastagem, em decorrência do controle da elevação do meristema apical.

Allden \& Whittaker (1970) afirmaram que, entre outros fatores, a altura do dossel afeta de forma direta o consumo dos animais em pastejo.

A elevação da altura da pastagem de gramíneas C4, ao contrário do que ocorre nas plantas C3, não mantém relação direta com a disponibilidade de forragem ao animal. Conforme aumenta a altura do dossel, ocorre diminuição na densidade da massa seca de lâminas foliares verdes, o que, segundo Stobbs (1973), compromete o tamanho do bocado.

Segundo Alexandrino et al. (2005), entre as estratégias de manejo da pastagem, deve-se contemplar o controle do alongamento do colmo. Além disso, nas gramíneas C4, as características mais relevantes para o comportamento ingestivo animal são a biomassa de forragem verde ou de folhas verdes e a proporção de folhas do estrato superior do dossel. Essa afirmação está de acordo com o observado por Rodrigues \& Reis (1995), que sugeriram o uso de lotação intermitente para controle do excessivo alongamento do colmo em gramíneas C4. Quando se decide por esse método, um dos principais fatores de manejo é a definição do período de descanso.

É importante estudar nas diversas regiões brasileiras e com várias espécies animais o período de descanso que otimiza o uso da forragem pelos animais e que garante perenidade ao sistema. Estudos conduzidos por Santos et al. (1999), Gomide et al. (1999), Alexandrino et al. (2005) e Cândido et al. (2005a,b,c) comprovaram que, para evitar os processos que comprometem o valor nutritivo e as características estruturais do dossel, o período de descanso não deve ser muito longo.

Outro aspecto importante no manejo das pastagens é a forma como se define o período de descanso. A definição do período de descanso com base na idade cronológica do dossel, apesar de facilitar a condução do pastejo de lotação intermitente, é biologicamente empírica, uma vez que a morfofisiologia do dossel varia conforme as condições de ambiente (Alexandrino et al., 2005). De fato, a pronta recuperação do dossel após pastejo está altamente correlacionada à produção de forragem, que depende do período de descanso, cuja duração deve garantir: restauração das reservas orgânicas (Fulkerson \& Donaghy, 2001), área foliar residual (Brougham, 1956), interceptação luminosa pelo dossel (Korte et al., 1982), perda por senescência e respiração (Parsons et al., 1983) e número de folhas vivas por perfilho (Fulkerson \& Slack, 1994).

Este trabalho foi realizado com o objetivo de avaliar as respostas morfológicas e estruturais do dossel de Panicum maximum cv. Tanzânia sob três períodos de descanso e suas implicações práticas no manejo das pastagens.

\section{Material e Métodos}

A pesquisa foi conduzida na Fazenda Experimental do Vale do Curu-FEVC, localizada no município de Pentecoste - CE e pertencente à Universidade Federal do Ceará - UFC. O clima da região é do tipo BShW' (classificação de Köeppen), semi-árido, com precipitação média anual de 806,5 mm, distribuída no período de janeiro a abril. O solo é classificado como neossolo flúvico (solos aluviais) (Embrapa, 1999) e está situado entre as latitudes $3^{\circ} 40^{\prime}$ a $3^{0} 51^{\prime} 18^{\prime \prime}$ sul e longitudes $39^{\circ} 10^{\prime} 19^{\prime \prime}$ e $39^{\circ} 18^{\prime} 13^{\prime \prime}$ oeste. A umidade relativa do ar média anual é de 73,8\%.

O experimento foi realizado em uma área de 1,5 ha de capim-tanzânia, estabelecida em janeiro de 2003, quando foi instalado o sistema de irrigação do tipo aspersão fixa de baixa pressão (Pressão de serviço $<2,0 \mathrm{kgf} / \mathrm{cm}^{2}$ ). A pastagem foi mantida em crescimento livre durante toda a estação chuvosa, sendo roçada no final do período das águas para uniformização da idade de rebrotação.

Foram avaliadas as características estruturais das pastagens mantidas sob três períodos de descanso, definidos de acordo com o tempo necessário para a expansão de 1,5; 2,5 e 3,5 novas folhas por perfilho após período de pastejo de cinco dias. 
A área foi dividida em seis unidades de pastejo, duas para cada período de descanso a ser avaliado. Como o período de pastejo foi de cinco dias e o filocrono estimado (Gomide \& Gomide, 1999) para a gramínea era de dez dias, foram feitas quatro, seis e oito subdivisões (piquetes) em cada uma das unidades de pastejo para os períodos de descanso de 1,5; 2,5 e 3,5 folhas, respectivamente, correspondendo a 15, 25 e 35 dias de descanso.

O delineamento experimental foi o inteiramente casualizado com duas repetições. Como foram proporcionados seis, quatro e três ciclos de pastejo para as pastagens sob períodos de descanso de 1,5; 2,5 e 3,5 folhas, respectivamente, e as medições foram feitas em todos os ciclos, obteve-se também o efeito dos ciclos de pastejo

A área de cada um dos piquetes dos períodos de descanso de 1,5; 2,5 e 3,5 folhas foi de 372, 223 e $160 \mathrm{~m}^{2}$, respectivamente, perfazendo um total de $8.212 \mathrm{~m}^{2}$. A área variável dos piquetes por tratamento foi adotada como primeira aproximação para se obter em todos eles a mesma oferta de forragem à entrada dos animais em cada piquete. O restante da área (aproximadamente 0,7 ha) foi utilizado como pastagem reserva. Foram utilizados 100 borregos sem raça definida (SRD), com peso inicial de $20 \mathrm{~kg}$, adquiridos em fazendas comerciais situadas no interior do Ceará. Foram utilizados oito animais por unidades de pastejo, perfazendo 16 animais-teste por período de descanso e totalizando 48 animais-teste, escolhidos por meio de sorteio. Os demais ovinos foram utilizados como animais de equilíbrio e permaneceram na área de reserva, sendo conduzidos, quando necessário, aos piquetes em pastejo para garantir o rebaixamento da vegetação e obter IAF em torno de 1,0 ao final do quinto dia.

A adubação teve como base a dose de $600 \mathrm{~kg}$ de N/ha/ano. A quantidade a ser aplicada foi obtida por meio da transformação da dose anual por hectare em dose diária por metro quadrado. A quantidade de nitrogênio a ser aplicada por piquete foi obtida pelo produto da multiplicação do período de descanso médio (dias) do piquete pela sua área $\left(\mathrm{m}^{2}\right)$ e deste resultado pela dose diária por $\mathrm{m}^{2}$.

Durante o período de descanso de cada piquete, foi registrado o número de folhas expandidas por perfilho e, ao final, um ou dois dias antes da entrada dos animais no piquete, foram amostrados dez perfilhos, contadas suas novas folhas expandidas e calculada a média para confirmar in loco se a condição pré-estabelecida para início do pastejo foi alcançada.

Ao final de cada período de descanso, anteriormente à entrada dos animais, foram feitas as seguintes avaliações nos piquetes pertinentes: altura do dossel, estimada medindo-se a altura em 35 pontos por piquete, utilizando-se uma régua graduada; e massas secas de forragem total (MSFT), de forragem morta (MSFM), de forragem verde (MSFV), de lâminas foliares verdes (MSLV), de colmos verdes (MSCV), relações material vivo/material morto (MV/ $\mathrm{MM}$ ) e folha/colmo, estimadas cortando-se em cada piquete duas amostras de $1,0 \times 1,0 \mathrm{~m}$, a $15 \mathrm{~cm}$ do solo. As amostras foram levadas ao laboratório, onde foram separados o material vivo do material morto e as lâminas foliares dos colmos do material vivo. Todas essas frações foram pesadas, secas em estufa de ventilação forçada a $65^{\circ} \mathrm{C}$ por 72 horas e, em seguida, foram pesadas novamente.

Ao final de cada período de pastejo, também foram feitas as seguintes avaliações em cada piquete: altura do dossel, MSFT, MSFM, MSFV, MSLV e MSCV, conforme descrito anteriormente, e a densidade populacional de perfilhos, estimada pela contagem do número de touceiras presentes em um retângulo de $2 \times 18 \mathrm{~m}$ e do número de perfilhos de duas touceiras representativas da condição média da pastagem naquele piquete.

Estimaram-se ainda as taxas de crescimento (TCC) e de acúmulo (TAC) da cultura durante o período de descanso, a partir das taxas de alongamento (TAlF) e senescência (TSF) de lâmina foliar, da taxa de alongamento dos colmos (TAlC) e da densidade populacional de perfilhos (DPP), conforme as seguintes equações, adaptadas de Davies (1983):

$$
\begin{aligned}
\mathrm{TAC} & =\{[(\mathrm{TAlF} \times \alpha 1)-(\mathrm{TSF} \times \alpha 2)]+(\mathrm{TAlC} \times \beta)\} \times \mathrm{DPP} \\
\mathrm{TCC} & =[(\mathrm{TAlF} \times \alpha 1)+(\mathrm{TAlC} \times \beta)] \times \mathrm{DPP},
\end{aligned}
$$

em que TCC = taxa de produção de forragem durante o período de descanso i ( $\mathrm{kg} \mathrm{MS/ha} \times$ dia); TAC = taxa de acúmulo de forragem durante o período de descanso i ( $\mathrm{kg}$ MS/ha $\times$ dia); TAlF = taxa de alongamento de lâmina foliar ( $\mathrm{cm} /$ perf $\times$ dia); $\alpha 1$ = índice de peso por unidade de comprimento de lâmina foliar emergente $(\mathrm{g} / \mathrm{cm})$; TSF $=$ taxa de senescência de lâmina foliar $(\mathrm{cm} /$ perf $\times$ dia $) ; \alpha 2$ = índice de peso por unidade de comprimento de lâmina foliar adulta $(\mathrm{g} / \mathrm{cm})$; TAlC = taxa de alongamento dos colmos ( $\mathrm{cm} /$ perf $\times$ dia); $\beta=$ índice de peso por unidade de comprimento de hastes $(\mathrm{g} / \mathrm{cm})$; DPP = densidade populacional de perfilhos no início do período de descanso i (perf/ha).

Os dados amostrados foram analisados por meio de modelagem utilizando-se o pacote estatístico SAS (SAS, 1999). O efeito dos períodos de descanso foi analisado inicialmente e, em seguida, foi estudado o efeito dos ciclos de pastejo dentro de cada período de descanso, segundo o modelo: 


$$
\mathrm{Y}_{\mathrm{ijk}}=\mu+\mathrm{T}_{\mathrm{i}}+\mathrm{C}_{(\mathrm{i}) \mathrm{j}}+\varepsilon_{\mathrm{ijk}}
$$

em que $\mathrm{Y}_{\mathrm{ijk}}=$ observação relativa ao $\mathrm{k}^{\mathrm{o}}$ piquete, no $\mathrm{j} \underline{\mathrm{o}}$ ciclo de pastejo, do io período de descanso; $\mu$ = média da população; $\mathrm{T}_{\mathrm{i}}=$ efeito do i⿳⺈ período de descanso e $\mathrm{i}=1$, 2, 3 períodos de descanso; $\mathrm{C}_{\mathrm{i}}=$ efeito do $\mathrm{j} \underline{\mathrm{o}}$ ciclo de pastejo, dentro do io período de descanso e $\mathrm{j}=3$, 4 ou 6 ciclos de pastejo; $\varepsilon_{\mathrm{ijk}}=$ efeito aleatório relativo de $\mathrm{k}^{\mathrm{o}}$ piquete, no jo ciclo de pastejo, do i⿳⺈ período de descanso; $\mathrm{k}=$ seis piquetes por tratamento (repetição).

\section{Resultados e Discussão}

Os três períodos de descanso pretendidos (1,5; 2,5 e 3,5 folhas expandidas por perfilho) foram atingidos de modo bem aproximativo (média de 1,48; 2,35 e 3,50 novas folhas expandidas por perfilho, respectivamente). Esses resultados comprovam que o objetivo proposto foi obtido. Os valores de índice de área foliar (IAF) residual foram semelhantes $(\mathrm{P}>0,05)$ em todas as fases para os períodos de descanso de 1,5 e 2,5 folhas (Tabela 1), porém, no PD 3,5 folhas, obteve-se o valor mais próximo do proposto $(1,0)$.

Ao observar os valores do período de descanso, expressos em dias, verifica-se que houve variações na resposta da pastagem ao longo dos ciclos de pastejo. Essa variação é reflexo das alterações no IAF residual ao longo dos ciclos de pastejo, que pode ter afetado de forma negativa, elevando o tempo necessário para a total recuperação da condição da pastagem. Esse comportamento pode ser atribuído ao possível déficithídrico ocorrido aos 30 dias após o início do experimento e ocasionado pela diminuição da eficiência de aplicação de água, em decorrência de problemas no sistema de irrigação.
Outro aspecto a ser destacado é o risco de se manejar a pastagem utilizando-se período de descanso pré-fixado em dias sem estudos sobre as respostas da pastagem às condições locais. Nessas circunstâncias, há risco de ocorrer, em determinados períodos, superpastejo e, em outras épocas, o subpastejo, que resulta em menor eficiência do sistema de produção.

Em estudo semelhante com capim-mombaça (Panicum maximum Jacq.) sob diferentes períodos de descanso (e estes definidos em número de folhas formadas após o pastejo), Cândido et al. (2005a,b) verificaram elevada variação na duração cronológica do período de descanso e revelaram intervalos de 24 a 41, 35 a 52 e 44 a 63 dias para os períodos de descanso correspondentes a 2,5, 3,5 e 4,5 folhas, respectivamente. Essa maior variação pode ter sido ocasionada pela maior variação das características climáticas ao longo dos ciclos de pastejo, como a diminuição da precipitação com o avançar dos ciclos de pastejo, fato de elevada relevância, uma vez que o experimento foi conduzido sem irrigação.

Verificou-se diferença $(\mathrm{P}<0,05)$ entre as pastagens sob os três períodos de descanso (Tabela 2). A pastagem sob PD 1,5 folha apresentou as menores alturas médias e aquela sob PD 3,5 folhas as maiores alturas médias. A maior freqüência de pastejo imposta aos piquetes sob PD 1,5 folha controlou a altura média do dossel. Comportamento semelhante foi descrito por Uebele (2002), que mencionou que a variável do manejo de maior importância no controle da elevação da altura do dossel é a freqüência de pastejo. O mesmo não foi observado nas pastagens sob os períodos de descanso de 2,5 e 3,5 folhas, cujas alturas pré-pastejo

Tabela 1 - Duração cronológica do período de descanso (PD), número de folhas por perfilho (NP) e índice de área foliar (IAF) residual em pastagem de capim-tanzânia

Table 1 - Resting period (PD) chronological duration, number of leaves per tiller (NP), and residual leaf area index (IAI) in Panicum maximum cv. Tanzania pastures

\begin{tabular}{|c|c|c|c|c|c|c|c|c|}
\hline \multirow[t]{2}{*}{$\begin{array}{l}\text { Variável } \\
\text { Variable }\end{array}$} & \multirow[t]{2}{*}{$\begin{array}{l}\mathrm{PD} \text { (folhas/perf) } \\
\text { Leaves/tiller }\end{array}$} & \multicolumn{6}{|c|}{$\begin{array}{l}\text { Ciclo de pastejo } \\
\text { Grazing cycle }\end{array}$} & \multirow[t]{2}{*}{$\begin{array}{l}\text { Média } \\
\text { Mean }\end{array}$} \\
\hline & & $1^{\underline{0}}$ & $2^{o}$ & $3 \underline{0}$ & $4 \underline{0}$ & $5 \underline{0}$ & $6 \underline{0}$ & \\
\hline \multirow{3}{*}{$\begin{array}{l}\mathrm{PD} \text { (dias) } \\
P D \text { (days) }\end{array}$} & 1,5 & 17,3 & 15,5 & 22,5 & 18,5 & 16,5 & 13,2 & 17,3 \\
\hline & 2,5 & 25,8 & 25,7 & 29,5 & 23,5 & - & - & 26,1 \\
\hline & 3,5 & 35,3 & 40,1 & 35,2 & - & - & - & 36,9 \\
\hline \multirow[t]{3}{*}{ NP } & 1,5 & $1,48 \mathrm{a}$ & $1,48 a$ & $1,62 \mathrm{a}$ & $1,48 a$ & $1,52 \mathrm{a}$ & $1,33 b$ & $1,48 \mathrm{C}$ \\
\hline & 2,5 & $2,61 \mathrm{a}$ & $2,26 \mathrm{c}$ & $2,50 \mathrm{ab}$ & $2,31 \mathrm{bc}$ & - & - & $2,42 B$ \\
\hline & 3,5 & $3,47 a$ & $3,55 a$ & 3,49a & - & - & - & $3,50 \mathrm{~A}$ \\
\hline \multirow{4}{*}{$\begin{array}{l}\text { IAF residual } \\
\text { Residual LAI }\end{array}$} & 1,5 & $1,25 a$ & $1,47 \mathrm{a}$ & $1,09 \mathrm{a}$ & $1,00 \mathrm{a}$ & $1,29 a$ & $1,14 a$ & $1,21 \mathrm{~A}$ \\
\hline & & & & & & & & \\
\hline & 2,5 & $1,08 \mathrm{a}$ & $1,47 \mathrm{a}$ & 1,46a & $1,08 \mathrm{a}$ & - & - & $1,27 \mathrm{~A}$ \\
\hline & 3,5 & $0,73 b$ & $1,26 a$ & $0,88 a b$ & - & - & - & $0,96 \mathrm{~B}$ \\
\hline
\end{tabular}

Médias seguidas de mesma letra minúscula nas linhas e maiúsculas nas colunas não diferem $(P>0,05)$ pelo teste $t$ de Student.

Means in the same row followed by the same small case letter and means in the same column followed by the same capital letters, do not differ (P>0.05) by t test of Student. 
elevaram-se com a continuidade dos ciclos de pastejo. Bueno (2003), estudando a resposta de capim-mombaça (Panicum maximum Jacq.) em diferentes períodos de descanso, também verificou elevação da altura do dossel com o prolongamento do período de descanso.

Esse resultado, confirmado neste estudo, demonstra a dificuldade de se manejarem gramíneas cespitosas como o capim-tanzânia com períodos de descanso mais longos. Esse resultado está relacionado ao fato de que, ao se atingir o IAF crítico, ocorre o alongamento dos colmos, ocasionado pelo sombreamento mútuo (Taiz \& Zeiger, 2004) e pela diminuição da qualidade e quantidade de luz no interior do dossel (Sbrissia \& Silva, 2001; Nabinger, 2002; Cândido et al., 2005a). Uma vez que, sob período de descanso de 2,5 folhas tenha-se atingido o IAF crítico e desencadeado o alongamento dos colmos, não é possível o total controle da elevação da altura no pré-pastejo nas pastagens sob períodos de descanso de 2,5 e 3,5 folhas.

As produções de MSFT, MSFV, MSLV e MSCV diferiram $(\mathrm{P}<0,05)$ entre os três períodos de descanso (Tabela 3). A pastagem sob o período de descanso de 1,5 folha apresentou os menores valores médios para essas variáveis e aquela sob o PD 3,5 folhas, os maiores valores médios. A MSFM foi maior e a relação MV/MM menor na pastagem sob PD 3,5 folhas em relação àquelas sob o PD 1,5 e 2,5 folhas. A relação F/C, no entanto, foi superior nas pastagens sob PD 1,5 e 2,5 folhas em relação àquela sob o PD 3,5 folhas.

Nas pastagens sob PD 2,5 e 3,5 folhas, verificou-se elevação das produções de MSFT, MSFV, MSLV e MSCV ao longo dos ciclos de pastejo. A pastagem sob PD 1,5 folha apresentou redução $(\mathrm{P}<0,05)$ do acúmulo de MSFM, a pastagem sob PD 2,5 folhas manteve-se constante e aquela sob PD 3,5 folhas apresentou tendência de elevação do acúmulo de MSFM com o avançar dos ciclos. Esse fato comprova que, de acordo com PD adotado, o processo de senescência varia ao longo dos ciclos de pastejo.

Bircham \& Hodson (1983) demonstraram certo atraso do processo de senescência em relação ao crescimento dos tecidos vegetais na rebrotação da pastagem e que o saldo desse processo, ou seja, a forragem acumulada, é o fator que efetivamente interessa à produção animal. No entanto, há um momento da rebrotação da pastagem a partir do qual é potencializado o processo de senescência. Nabinger (2002) mencionou que a utilização da massa de forragem produzida deve ocorrer antes que o dossel intercepte o máximo da radiação incidente, portanto, antes que seja desencadeado o processo de senescência.

Acredita-se que, ao ter atingido o IAF crítico, ainda no PD 2,5 folhas, o processo de senescência tenha aumentado e que, quando proporcionado maior tempo ao crescimento da pastagem (PD 3,5 folhas), a senescência tenha-se acentuado, fato comprovado pela grande quantidade de material morto na pastagem sob PD 3,5 folhas.

O aumento da produção de massa de forragem foi ocasionado tanto pelo maior tempo de crescimento quanto pelo aumento da produção de massa de colmos (MSCV), especialmente no PD 3,5 folhas. Nesse período de descanso, verificou-se elevação média de $185 \%$ no ciclo final em relação ao primeiro ciclo, enquanto na pastagem sob PD 2,5 folhas esse aumento correspondeu a aproximadamente $90 \%$. O aumento na MSLV ao longo dos ciclos correspondeu a 53 e $62 \%$ para as pastagens sob os PD 2,5 e 3,5 F, respectivamente.

Resposta similar foi verificada por Penati (2002) e Cândido et al. (2005a), também em capim-mombaça. No entanto, Cândido et al. (2005a) avaliaram a resposta da pastagem sob pastejo de bovinos e, no período de descanso de 2,5 folhas, verificaram comportamento similar ao observado neste estudo na pastagem sob período de descanso de 1,5 folha, que diferiu do período de descanso de 2,5 folhas. A mudança na resposta da pastagem sob período de descanso de 2,5 folhas pode ser atribuída à diferença no hábito de crescimento da pastagem (crescimento mais prostrado), em decorrência da espécie animal e do resíduo utilizados. Conseqüentemente, atingiu-se o IAF crítico mais cedo, desencadeando o alongamento dos colmos e o

Tabela 2 - Altura pré-pastejo $(\mathrm{cm})$ do dossel de capim-tanzânia ( $P$. maximum Jacq.) em pastagem de capim-tanzânia manejada sob diferentes períodos de descanso (PD) e ciclos de pastejo

Table 2 - Pre-grazing canopy height (cm) of tanzaniagrass (P. maximum Jacq.) pastures managed under different resting periods (PD) and grazing cycles

\begin{tabular}{|c|c|c|c|c|c|c|c|}
\hline \multirow[t]{2}{*}{$\begin{array}{l}\mathrm{PD} \text { (folhas/perf) } \\
\text { Leaves/tiller }\end{array}$} & \multicolumn{6}{|c|}{$\begin{array}{l}\text { Ciclo de pastejo } \\
\text { Grazing cycle }\end{array}$} & \multirow[t]{2}{*}{$\begin{array}{l}\text { Média } \\
\text { Mean }\end{array}$} \\
\hline & $1 \underline{o}$ & $2 \underline{0}$ & $3 \underline{0}$ & $4^{\circ}$ & $5 \underline{0}$ & $6 \underline{0}$ & \\
\hline 1,5 & $44,7 a$ & $45,6 a$ & $50,0 \mathrm{a}$ & $45,6 a$ & $50,3 a$ & $47,4 a$ & $47,3 \mathrm{C}$ \\
\hline 2,5 & $50,0 \mathrm{~b}$ & $64,4 a$ & $70,0 \mathrm{a}$ & $71,7 a$ & - & - & $64,0 \mathrm{~B}$ \\
\hline 3,5 & $67,5 b$ & $72,4 b$ & $88,2 \mathrm{a}$ & - & - & - & $76,1 \mathrm{~A}$ \\
\hline
\end{tabular}

Médias seguidas de mesma letra minúscula nas linhas e maiúsculas nas colunas não diferem $(P>0,05)$ pelo teste $t$ de Student. Means in the same row followed by the same small letter and means in the same column followed by the same capital letters, do not differ $(P>0.05)$ by t test of Student. 
Tabela 3 - Massa seca de forragem total (MSFT), de forragem morta (MSFM), de forragem verde (MSFV), de lâminas foliares verdes (MSLV), de colmos verdes (MSCV), relação material vivo/material morto (MV/MM) e relação folha/colmo (F/C) em pastagem de capim-tanzânia manejada sob três períodos de descanso e ao longo de ciclos de pastejo sucessivos

Table 3 - Pre-grazing total forage mass (MSFT), dead forage mass (MSFM), green forage mass (MSFV), green blade mass (MSLV), green stem mass (MSCV), and live/dead mateial (MVIMM) and leaf/stem (F/C) ratios in Panicum maximum cv Tanzania pastures under three resting periods (PDs) along succeeding grazing cycles

\begin{tabular}{|c|c|c|c|c|c|c|c|c|}
\hline \multirow[t]{2}{*}{$\begin{array}{l}\text { Variável } \\
\text { Variable }\end{array}$} & \multirow[t]{2}{*}{$\begin{array}{l}\mathrm{PD} \text { (folhas/perf) } \\
\text { Leaves/tiller }\end{array}$} & \multicolumn{6}{|c|}{$\begin{array}{c}\text { Ciclo de pastejo } \\
\text { Grazing cycle }\end{array}$} & \multirow[t]{2}{*}{$\begin{array}{l}\text { Média } \\
\text { Mean }\end{array}$} \\
\hline & & $1 \underline{0}$ & $2^{0}$ & $3 \underline{0}$ & $4 \underline{0}$ & $5 \underline{0}$ & $6 \underline{0}$ & \\
\hline \multirow{2}{*}{ MSFT (kg/ha) } & 2,5 & $2.918 c$ & $3.878 b$ & $5.254 \mathrm{a}$ & $4.452 \mathrm{ab}$ & - & - & $4.125 \mathrm{~B}$ \\
\hline & 3,5 & 3951c & $5.030 \mathrm{~b}$ & $7.602 \mathrm{a}$ & - & - & - & $5.528 \mathrm{~A}$ \\
\hline MSFM (kg/ha) & 1,5 & $683 a$ & 451ab & $4.76 a b$ & $434 a b$ & $324 b$ & $362 \mathrm{ab}$ & 455B \\
\hline \multirow[t]{3}{*}{ MSFV (kg/ha) } & 1,5 & $2.094 b$ & $2.307 a b$ & $2.589 a$ & $2.275 \mathrm{ab}$ & $2.675 a$ & $1954 b$ & $2.316 \mathrm{C}$ \\
\hline & 2,5 & $2.362 \mathrm{c}$ & 3417b & $4.433 a$ & $3.854 \mathrm{ab}$ & - & - & $3.516 \mathrm{~B}$ \\
\hline & 3,5 & $3.069 c$ & $4008 b$ & $6.296 a$ & - & - & - & $4.454 \mathrm{~A}$ \\
\hline \multirow[t]{3}{*}{$\mathrm{MV} / \mathrm{MM}$} & 1,5 & 6,46b & $6,45 b$ & $5,84 b$ & $6,64 b$ & $13,3 a$ & $7,47 \mathrm{~b}$ & 7,70A \\
\hline & 2,5 & $5,53 a$ & $6,99 a$ & $7,74 a$ & $11,6 a$ & - & - & $7,95 \mathrm{~A}$ \\
\hline & 3,5 & 3,95a & $4,12 \mathrm{a}$ & $5,24 a$ & - & - & - & 4,44B \\
\hline \multirow{2}{*}{ MSCV (kg/ha) } & 2,5 & $401 \mathrm{~b}$ & $565 a b$ & $910 a$ & $762 \mathrm{ab}$ & - & - & $659 B$ \\
\hline & 3,5 & $581 b$ & $894 b$ & $1.658 \mathrm{a}$ & - & - & - & $1.044 \mathrm{~A}$ \\
\hline \multirow[t]{3}{*}{$\mathrm{F} / \mathrm{C}$} & 1,5 & $5,49 b$ & $5,37 b$ & $9,25 a$ & $8,81 \mathrm{ab}$ & $11,0 \mathrm{a}$ & $6,64 a b$ & 7,75A \\
\hline & 2,5 & $6,28 a$ & $5,47 a$ & $5,76 a$ & $5,24 a$ & - & - & $5,69 \mathrm{~A}$ \\
\hline & 3,5 & $4,73 a$ & $3,6 a b$ & $2,78 b$ & - & - & - & $3,70 \mathrm{~B}$ \\
\hline
\end{tabular}

Médias seguidas de mesma letra minúscula nas linhas e maiúsculas nas colunas não diferem $(P>0,05)$ pelo teste $t$ de Student.

Means in the same row followed by the same small letter and means in the same column followed by the same capital letters, do not differ ( $P>0.05)$ by t test of Student.

aumento da produção de MSFT, atribuído, em grande parte, ao aumento da produção de colmos.

Na pastagem sob PD 1,5 folha, verificou-se tendência de declínio nos valores referentes às MSFT, MSFV, MSLV e MSFM, o que confirma o possível processo de degradação da pastagem sob esse período de descanso, relacionado aos fatores restritivos (maior freqüência e alta intensidade de pastejo).

A pastagem sob $\mathrm{PD} 3,5$ folhas diferiu $(\mathrm{P}<0,05)$ daquelas sob os períodos de descanso de 1,5 e 2,5 folhas, que foram similares (Tabela 3). A relação F/C na pastagem sob período de descanso de 1,5 folha aumentou do primeiro até o quinto ciclo de pastejo, quando apresentou redução brusca. Esse resultado, em parte, é reflexo da maior redução da produção de MSLV em comparação à produção de MSCV neste ciclo. A pastagem sob PD 2,5 folhas apresentou relação $\mathrm{F} / \mathrm{C}$ constante e a pastagem sob período de descanso de 3,5 folhas apresentou diminuição com o avançar dos ciclos de pastejo.

Mesma tendência foi verificada por Santos et al. (1999), em P. maximum cv. Mombaça e Tanzânia sob freqüência de pastejo de 28 a 48 dias, e Cândido et al. (2005c) ,em capim-mombaça ( $P$. maximum Jacq.) sob freqüência de pastejo de 24 a 63 dias. Teixeira et al. (1999), em pesquisa com P. maximum Jacq. cv. Tobiatã, também verificaram mesma tendência dessa cultivar submetida ao pastejo de bovinos com período de descanso de 33 dias.

A diminuição da relação folha/colmo e, conseqüentemente, a diminuição relativa da oferta de folhas e da forma como é disponibilizada ao animal afetam o consumo, uma vez que a qualidade das lâminas foliares é superior à dos colmos e que as lâminas são constituídas de tecidos de mais fácil fragmentação e digestão (Akin, 1989).

Houve diferença $(\mathrm{P}<0,05)$ entre as pastagens quanto à altura pós-pastejo do dossel (Tabela 4). A pastagem sob menor período de descanso (1,5 folha) apresentou os menores valores médios de altura no pós-pastejo. Na pastagem sob PD 3,5 folhas, verificaram-se os maiores valores médios de altura do dossel no pós-pastejo. Ao longo dos ciclos de pastejo, verificaram-se manutenção da altura da pastagem sob o PD 1,5 folha e elevação nas pastagens sob os períodos de descanso de 2,5 e 3,5 folhas.

O aumento na altura do dossel foi ocasionado pela elevação dos colmos nas pastagens sob os períodos de descanso de 2,5 e 3,5 folhas. Essa elevação pode ser atribuída aos processos de sombreamento mútuo, compe- 
Tabela 4 - Altura pós-pastejo (cm) do dossel em pastagens de capim-tanzânia sob três períodos de descanso (PD)

Table 4 - Post-grazing canopy height (cm) of Panicum maximum cv Tanzania pastures under three resting periods (PDs) along succeeding grazing cycles

\begin{tabular}{|c|c|c|c|c|c|c|c|}
\hline \multirow[t]{2}{*}{$\begin{array}{l}\mathrm{PD} \text { (folhas/perf) } \\
\text { Leaves/tiller }\end{array}$} & \multicolumn{6}{|c|}{$\begin{array}{c}\text { Ciclo de pastejo } \\
\text { Grazing cycle }\end{array}$} & \multirow[t]{2}{*}{$\begin{array}{l}\text { Média } \\
\text { Mean }\end{array}$} \\
\hline & $1^{0}$ & $2^{0}$ & $3^{0}$ & $4^{\circ}$ & $5 \underline{0}$ & $6 \underline{0}$ & \\
\hline 1,5 & $24,9 \mathrm{a}$ & $25,7 a$ & $25,4 a$ & $24,9 a$ & $25,5 \mathrm{a}$ & $23,8 a$ & $25,0 \mathrm{C}$ \\
\hline 2,5 & $28,1 \mathrm{c}$ & $30,1 \mathrm{bc}$ & $34,9 a$ & $34,4 \mathrm{ab}$ & - & - & $31,8 \mathrm{~B}$ \\
\hline 3,5 & $30,4 b$ & $40,7 \mathrm{a}$ & $42,6 a$ & - & - & - & $37,9 \mathrm{~A}$ \\
\hline
\end{tabular}

Médias seguidas de mesma letra minúscula nas linhas e maiúscula nas colunas não diferem $(P>0,05)$ pelo teste $t$ de Student.

Means followed by the same small letter within a row and capital in a column do not differ $(P>0.05)$ by $t$ test of Student.

tição por luz e desencadeamento do alongamento de hastes. Como a condição residual preconizada era em termos de índice de área foliar e, nas pastagens sob PD 2,5 e 3,5 folhas houve intensificação do alongamento dos colmos, uma mesma condição de IAF residual representou alturas diferenciadas do resíduo pós-pastejo. Mesma tendência foi verificada por Cândido et al. (2005b) em pastagem de capimmombaça. Esses autores encontraram na pastagem sob menor período de descanso manutenção da altura póspastejo, na qual houve maior controle na elevação de hastes, diferindo da pastagem sob o PD 2,5 folhas avaliada neste estudo. Nas pastagens sob períodos de descanso de 3,5 e 4,5 folhas, não foi possível o controle da altura do resíduo em virtude do alongamento dos colmos, resposta similar à verificada nas pastagens sob períodos de descanso de 2,5 e 3,5 folhas avaliadas neste estudo. Bueno (2003), estudando a interação interceptação luminosa $\times$ resíduo pós-pastejo, verificou que, no resíduo proveniente da pastagem sob período de descanso de $95 \%$ de interceptação da radiação incidente, houve manutenção da altura. No período de descanso $100 \%$ de interceptação da radiação incidente, não houve controle da altura no resíduo. Desse modo, confirma-se a atuação do sombreamento mútuo a partir do IAF crítico (primeiro valor de IAF que intercepta 95\% da radiação incidente) no desencadeamento do processo de elevação dos colmos.

As MSFT, MSFM e MSCV residuais da pastagem sob $\mathrm{PD} 3,5$ folhas foram superiores $(\mathrm{P}<0,05)$ às das pastagens sob os PDs 1,5 folha e 2,5 folhas (Tabela 5). A contribuição no aumento da MSFT residual pela MSFV residual decorreu da elevação na quantidade de colmos produzidos rejeitados pelos ovinos, visto que a MSLV residual nesse ciclo foi reduzida. A MV/MM residual da pastagem sob PD 2,5 folhas foi similar à daquela sob o PD 1,5 folha e superior $(\mathrm{P}<0,05)$ à da pastagem sob PD 3,5 folhas. Esse comportamento pode ser atribuído à maior elevação na MSFM residual na pastagem sob PD 3,5 folhas, ocasionando diminuição na MV/MM. A relação folha/colmo residual da pasta- gem sob PD 3,5 folhas foi inferior $(\mathrm{P}<0,05)$ à relação obtida nas demais pastagens. Como o resíduo foi definido de acordo com o IAF e este índice é o mesmo para todos e guarda relação com a MSLV, a redução da relação folha/ colmo deveu-se à maior presença de colmos na pastagem sob PD 3,5 folhas (Tabela 5). Esse mesmo comportamento foi verificado por Gomide \& Gomide (1999) e Cândido et al. (2005c), em pesquisa com capim-mombaça sob três período de descanso. Segundo esses autores, o maior acúmulo de colmos ocorreu no maior período de descanso, processo inerente às espécies de gramíneas $\mathrm{C}_{4}$ submetidas a baixa freqüência de desfolhação.

A redução na MSFT reflete a diminuição da MSFV e MSFM (maior proporção). A redução na MSFV deveu-se às reduções de $16 \%$ na MSLV e de $26 \%$ na MSCV. A maior redução da MSCV em relação à MSLV pode ser reflexo do ajuste da planta na partição de carbono em caso de restrições, situação em que, segundo Nabinger (2002), a folha é a última a ser penalizada em detrimento às outras partes da planta. Esse efeito pode ser percebido quando avaliada a densidade populacional de perfilhos da pastagem sob o PD 1,5 folha, que também reduziu no mesmo período. A relação folha/colmo foi variável ao longo dos ciclos e apresentou o maior valor no $3^{0}$ ciclo e depois tendeu a diminuir, mantendo-se próximo de 2,0 na pastagem sob PD 2,5 folhas.

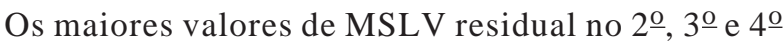
ciclos refletiram diretamente no IAF residual da pastagem sob o PD 2,5 folhas, provocando aumento dessa variável (Tabela 5). A maior produção de MSLV na pastagem sob PD 2,5 folhas, que refletiu em IAF residual superior ao IAF residual da pastagem sob PD 3,5 folhas e foi semelhante ao da pastagem sob o PD 1,5 folha, juntamente com a menor freqüência de pastejo utilizada na pastagem sob o PD 1,5 folha, pode ter lhe conferido melhor condição de rebrota, diminuindo o período de participação das reservas do colmo para formação de novas folhas e restaurando mais rapidamente os teores de carboidratos totais não-estruturais (CTNE), como 
Tabela 5 - Massa seca de forragem total (MSFT), de forragem morta (MSFM), de forragem verde (MSFV), de lâminas foliares verdes (MSLV), de colmos verdes (MSCV), relação material vivo/material morto (MV/MM) e relação folha/colmo (F/C) em pastagens de capim-tanzânia sob três períodos de descanso

Table 5 - Post-grazing total forage mass (MSFT), dead forage mass (MSFM), green forage mass (MSFV), green blade mass (MSLV), green stem mass (MSCV), live/dead material ratio (MV/MM), and leaf/stem (F/C) ratio in Panicum maximum cv Tanzania pastures under three resting periods (PDs) along succeeding grazing cycles

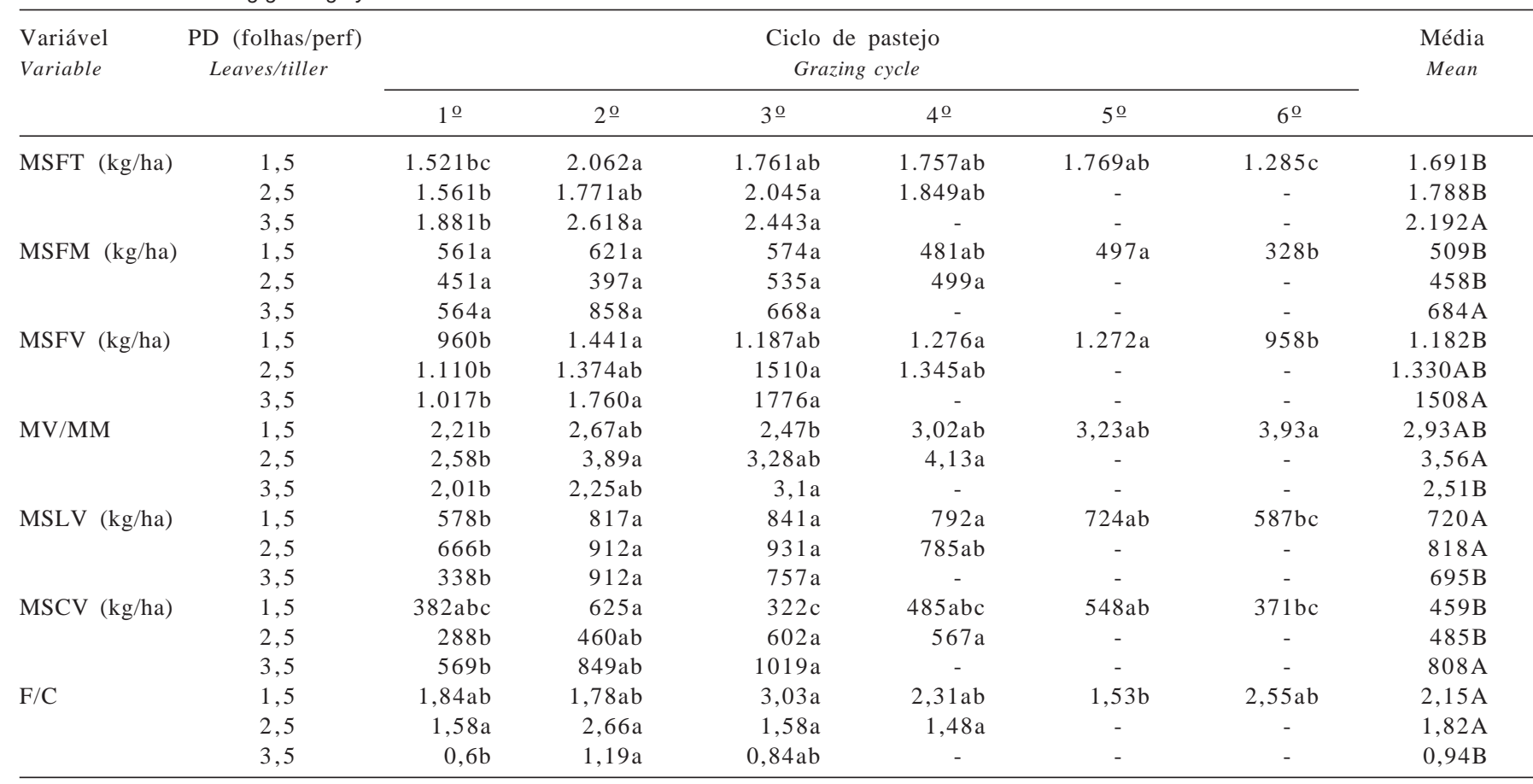

Médias seguidas de mesma letra minúscula nas linhas e maiúscula nas colunas não diferem $(P>0,05)$ pelo teste $t$ de Student.

Means followed by the same small letter within a row and capital in a column do not differ $(P>0.05)$ by t test of Student.

verificado por Gomide \& Gomide (1999), em estudo similar, porém com capim-mombaça ( $P$. maximum Jacq.) pastejado por bovinos e sob período de descanso relativo ao tempo necessário à formação de 2,5 novas folhas.

Na pastagem sob PD 3,5 folhas, houve redução da MSFT no $3^{\circ}$ ciclo, como reflexo da diminuição na MSFM e da manutenção da MSFV. Para a MSFV, no entanto, houve tendência de elevação da MSCV e diminuição da MSLV, mantendo desse modo a MSFV. Essa condição de menor MSLV refletiu diretamente no IAF residual do 3 o ciclo de pastejo desse período de descanso, no qual o valor de IAF foi inferior $(0,88)$ ao preconizado $(1,00)$, o que caracteriza elevada intensidade de pastejo. A tendência de redução da MSFM deveu-se ao fato de que o animal, não mais dispondo de lâminas foliares vivas suficientes em quantidade e qualidade (terço inferior, rico em tecidos de sustentação e de mais difícil ruptura), também rejeitou os colmos e passou a consumir a lâminas foliares mortas constituintes da MSFM. A possibilidade de diminuição da MSFM em decorrência da decomposição é pequena e, se ocorresse com o período de descanso de 3,5 folhas, ocorreria também nos demais.

As relações MV/MM e folha/colmo foram reduzidas em relação ao pré-pastejo, uma vez que o animal tem preferência por tecidos verdes, especialmente lâminas foliares.

Entre os ciclos, o que se verificou nas pastagens sob os três períodos de descanso foi elevação da MSLV residual dos ciclos de pastejo iniciais ao meio da fase experimental, com redução no sentido dos ciclos de pastejo finais. Na pastagem sob o PD 3,5 folhas, foi reflexo da não obtenção da condição residual preconizada (IAF 1), o que resultou em menor MSLV.

A relação folha/colmo da pastagem sob o PD 1,5 folha apresentou resposta variável ao longo dos ciclos de pastejo sucessivos, com tendência de elevação do ciclo inicial ao terceiro ciclo e redução posterior até o quinto ciclo de pastejo, elevando-se no sexto ciclo de pastejo. A relação folha/colmo na pastagem sob o PD 2,5 folhas apresentou tendência de aumento do primeiro para o segundo ciclo de pastejo e retornou a valores semelhantes ao verificado no primeiro ciclo mantendo-se ao longo dos ciclos sucessivos de pastejo. A relação folha/colmo da pastagem sob o PD 3,5 folhas apresentou mesma resposta da MSLV e IAF residual, reflexo da reduzida MSLV nos ciclos 1 e 3. A reduzida MSLV, por sua vez, foi determinada pela maior pressão de pastejo (não desejada) imposta no PD 3,5 folhas. 
A DPP da pastagem sob o PD 2,5 folhas foi similar à verificada sob $\mathrm{PD} 1,5$ folha e superior $(\mathrm{P}<0,05)$ à verificada no PD 3,5 folhas (Tabela 6). As diferenças foram evidenciadas ao longo do experimento, de modo que, na pastagem sob o PD 1,5 folha, houve aumento da DPP até o meio do período experimental e redução dessa variável nos dois últimos ciclos. A alta intensidade de pastejo e a maior freqüência de pastejo utilizada no PD 1,5 folha, associada à diminuição da eficiência de aplicação da água e ao menor aporte de N, pode ter atuado de forma negativa, uma vez que, com a restrição de fatores relacionados ao crescimento e ao desenvolvimento vegetal, um dos primeiros mecanismos de adaptação desencadeado pela planta é a diminuição da emissão de novos perfilhos (Davies et al., 1983; Gomide \& Gomide, 1999; Lemaire, 2001; Nabinger, 2002; Nabinger \& Pontes, 2001), o que pode ter ocasionado diminuição da DPP no último ciclo da pastagem sob o PD 1,5 folha. Outro aspecto a ser observado é o arranquio de perfilhos pelo animal, uma vez que ainda estariam tenros e facilmente removíveis, especialmente por ovinos, animais que pastejam muito rente ao solo. Bircham \& Hodgson (1983), estudando o comportamento dos componentes do fluxo de biomassa e da estrutura de pastagens mistas de clima temperado, também relataram menor DPP na pastagem mais intensivamente manejada e também atribuíram esse fato ao arranquio de perfilhos mais fracos pelos ovinos em pastejo.

A pastagem sob PD 2,5 folhas apresentou redução na DPP no $3^{0}$ ciclo de pastejo, provavelmente em resposta às limitações hídricas e nutricionais verificadas nesse ciclo. O grande sombreamento mútuo em maior IAF esperado para a pastagem sob o PD 3,5 folhas, em relação àquela sob PD 2,5 folhas, atuaria inibindo a brotação das gemas localizadas da base da touceira, em decorrência da menor disponibilidade de luz em quantidade e qualidade (Nabinger, 2002; Nabinger \& Pontes, 2001). Assim, houve o processo de compensação tamanho $\times$ número de perfilhos, que determinou uma faixa de resposta plástica, incidindo acúmulo ótimo de forragem (Grant et al., 1983, citados por Sbrissia \& Silva, 2001). Os valores foram superiores aos encontrados por Cândido et al. (2005a) e Gomide \& Gomide (1999), possivelmente porque o cultivar estudado por esses autores (Panicum maximum Jacq. cv. Mombaça) tem menor capacidade de perfilhamento. Além disso, em ambas as pesquisas foram utilizados bovinos e deixado IAF residual igual ou superior a 2,0, o que pode ter conferido melhor condição de rebrotação, atingindo mais rapidamente IAF que desencadeassem o sombreamento mútuo, inibindo o perfilhamento.

Tabela 6 - Densidade populacional de perfilhos (DPP) em pastagens de capim-tanzânia sob três períodos de descanso (PD)

Table 6 - Post-grazing tiller population density (DPP) in Panicum maximum cv. Tanzania paddocks under three resting periods (PDs) along succeeding grazing cycles

\begin{tabular}{|c|c|c|c|c|c|c|c|}
\hline \multirow[t]{2}{*}{$\begin{array}{l}\mathrm{PD} \text { (folhas/perf) } \\
\text { Leaves/tiller }\end{array}$} & \multicolumn{6}{|c|}{$\begin{array}{l}\text { Ciclo de pastejo } \\
\text { Grazing cycle }\end{array}$} & \multirow[t]{2}{*}{$\begin{array}{l}\text { Média } \\
\text { Mean }\end{array}$} \\
\hline & $1^{0}$ & $2 \underline{0}$ & $3 \underline{0}$ & $4^{\circ}$ & $5 \underline{0}$ & $6 \underline{0}$ & \\
\hline 1,5 & 416bcd & $475 a b$ & $573 a$ & $436 \mathrm{bc}$ & 333d & $352 c d$ & $431 \mathrm{AB}$ \\
\hline 2,5 & 479ab & $559 a$ & $410 \mathrm{~b}$ & 433ab & - & - & $472 \mathrm{~A}$ \\
\hline 3,5 & 449a & $383 a$ & $303 b$ & - & - & - & $378 B$ \\
\hline
\end{tabular}

Médias seguidas de mesma letra minúscula nas linhas e maiúscula nas colunas não diferem $(P>0,05)$ pelo teste $t$ de Student.

Means followed by the same small letter within a row and capital in a column do not differ $(P>0.05)$ by $t$ test of Student.

Tabela 7 - Taxas de crescimento (TCC) e de acúmulo (TAC) de forragem (kg MS/ha/dia) estimadas pelo método agronômico em pastagem de capim-tanzânia sob três períodos de descanso

Table 7 - Crop growth rate (TCC) and herbage net accumulation rate (TAC), estimated by the agronomic method in Panicum maximum cv Tanzania pastures under three resting periods (PDs) along succeeding grazing cycles

\begin{tabular}{|c|c|c|c|c|c|c|c|c|}
\hline \multirow[t]{2}{*}{$\begin{array}{l}\text { Variável } \\
\text { Variable }\end{array}$} & \multirow[t]{2}{*}{$\begin{array}{l}\mathrm{PD} \text { (folhas/perf) } \\
\text { Leaves/tiller }\end{array}$} & \multicolumn{6}{|c|}{$\begin{array}{c}\text { Ciclo de pastejo } \\
\text { Grazing cycle }\end{array}$} & \multirow[t]{2}{*}{$\begin{array}{l}\text { Média } \\
\text { Mean }\end{array}$} \\
\hline & & 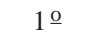 & $2 \underline{0}$ & $3 \underline{0}$ & $4 \underline{0}$ & $5 \underline{0}$ & $6 \underline{0}$ & \\
\hline TCC & 1,5 & - & $78,7 a$ & $44,5 \mathrm{ab}$ & $49,1 \mathrm{ab}$ & 75,3 а & $41,4 \mathrm{~b}$ & $58,3 \mathrm{~B}$ \\
\hline \multirow[t]{2}{*}{ (kg MS/ha*dia) } & 2,5 & $64,8 b$ & $90,2 \mathrm{ab}$ & $118,1 \mathrm{a}$ & $102,4 \mathrm{ab}$ & - & - & $96,5 \mathrm{~A}$ \\
\hline & 3,5 & $79,2 b$ & $86,0 \mathrm{~b}$ & $141,6 \mathrm{a}$ & - & - & - & $103,6 \mathrm{~A}$ \\
\hline \multirow{3}{*}{ (kg MS/ha*dia) } & 1,5 & - & $102,8 \mathrm{a}$ & $51,0 \mathrm{~b}$ & $55,8 b$ & $84,8 a$ & $51,7 b$ & $68,5 \mathrm{~B}$ \\
\hline & 2,5 & $61,6 b$ & $89,8 \mathrm{a}$ & $103,7 \mathrm{a}$ & $99,8 a$ & - & - & $91,2 \mathrm{~A}$ \\
\hline & 3,5 & $61,3 b$ & $74,6 \mathrm{~b}$ & $128,8 \mathrm{a}$ & - & - & - & $89,8 \mathrm{~A}$ \\
\hline
\end{tabular}

Médias seguidas de mesma letra minúscula nas linhas e maiúscula nas colunas não diferem $(P>0,05)$ pelo teste $t$ de Student.

Means followed by the same small letter within a row and capital in a column do not differ $(P>0.05)$ by $t$ test of Student. 
A TCC e a TAC obtidas na pastagem sob o 1,5 folha (Tabela 7) foram inferiores às demais $(\mathrm{P}<0,05)$. Entretanto, a taxa de acúmulo da cultura (TAC) foi maior na pastagem submetida a PD 1,5 folha em relação àquela sob PD 2,5 folhas e apresentou tendência de diminuição em relação àquela sob o PD 3,5 folhas, ou seja, a vantagem de crescimento da pastagem sob PD mais longo foi dissipada quando se debitou a fração morta, que tinha contribuição muito expressiva na massa de forragem total (Tabela 3).

Santos et al. (1999), estudando os capins mombaça e tanzânia ( $P$. maximum), não observaram diferença na taxa de acúmulo de MS (kg/ha*dia) nos piquetes sob PD de 28, 38 e 48 dias em lotação rotacional, o que difere do observado nesse estudo. No entanto, quando observadas somente as pastagens sob PD 2,5 e 3,5 F, que corresponderam aos períodos de descanso de 28 e 38 dias, respectivamente, verifica-se que essas pastagens apresentaram o mesmo comportamento. Gomide \& Gomide (1999), estudando capimmombaça ( $P$. maximum) em três períodos de descanso (2,5; 3,5 e 4,5 folhas), encontraram valores de 159,5 a 182,8 kg $\mathrm{MS} / \mathrm{ha} /$ dia (o maior valor foi obtido na pastagem sob PD 2,5 folhas). Cândido et al. (2005a), estudando o mesmo cultivar, verificaram valores de TCC, pelo método da morfogênese, de 93 a 202 kg MS/ha/dia (o primeiro se refere à pastagem sob PD 3,5 folhas e o segundo, à pastagem sob PD de 2,5 F). Mello (2002), estudando capim-tanzânia (P. maximum) sob lotação rotativa com PD de 33 dias, com três resíduos pós-pastejo, adubação nitrogenada correspondente a 800 kg e irrigação, verificou TCC média de $88,7 \mathrm{~kg} \mathrm{MS} / \mathrm{ha} /$ dia, valor muito próximo ao encontrado nesta pesquisa $(86,1)$. Ressalta-se que a dose de $\mathrm{N}$ utilizada neste estudo, equivalente a $600 \mathrm{~kg}$ de N/ha/ano, foi inferior à utilizada por esse autor.

O valor inferior da TCC em relação à TAC na pastagem sob PD 1,5 folha não estava previsto, uma vez que a TAC faz parte da TCC. Possivelmente, diferenças nas proporções de material vivo/material morto no resíduo e no pré-pastejo expliquem esse fato. O aumento dessa relação foi de $165 \%$ durante o PD 1,5 folha e reduziu para $122 \%$ na pastagem sob o PD 2,5 folhas e para 76\% na pastagem sob o PD 3,5 folhas, ou seja, a produção de novos tecidos na pastagem sob período de descanso mais curto pode ter sido mais intensa e estar associada à perda de material morto acima da altura de corte da amostra destrutiva.

Os dados obtidos nesta pesquisa na pastagem sob PD 2,5 folha foram superiores e os encontrados sob PD 1,5 e 3,5 folhas, similares aos valores médios encontrados por Bueno (2003), em experimento com P. maximum cv. Mombaça. Esse autor verificou, pelo método agronômico, ao longo de um ano, valores de TCC de 24 a 125 kg MS/ha/dia e, quando avaliado somente o período do verão (período de maior crescimento), os valores mantiveram-se entre $92 \mathrm{e}$ $125 \mathrm{~kg} \mathrm{MS} / \mathrm{ha} /$ dia.

\section{Conclusões}

O prolongamento do período de descanso acarretou maiores alturas pré e pós-pastejo e aumento no acúmulo de massa seca de forragem total, com proporção crescente de colmos e material morto. O período de descanso em capimtanzânia pastejado por ovinos não deve exceder o tempo necessário para expansão de 2,5 novas folhas por perfilho. Considerando a tendência de redução na densidade de perfilhos, o que comprometeria a sustentabilidade do sistema, sugere-se que a utilização do período de descanso referente à expansão de 1,5 folha seja melhor estudada antes de ser recomendada.

\section{Literatura Citada}

AKIN, D.E. Histological and phisical factors affecting digestibility of forages. Agronomy Journal, v.81, n.1, p.17-25, 1989.

ALEXANDRINO, E.; GOMIDE, C.A.M.; CÂNDIDO, M.J.D. et al. Período de descanso, características estruturais do dossel e ganho de peso vivo de novilhos em pastagem de capim-mombaça sob lotação intermitente. Revista Brasileira de Zootecnia, v.34, n.6, p.2174-2184, 2005 (supl.)

ALLDEN, W.G.; WHITTAKER, I.A. The determinants of herbage intake by grazing sheep: the interrelationship of factors influencing herbage intake and availability. Australian Journal of Agricultural Research, v.21, n.5, p.755-766, 1970.

BIRCHAM, J.S.; HODGSON, J. The influence of sward condition on rates of herbage growth and senescence in mixed swards under continuous stocking management. Grass and Forage Science, v.38, n.4, p.323-331, 1983.

BROUGHAM, R.W. Effect of intensity of defoliation on regrowth of pasture. Australian Journal of Agricultural Research, v.7, n.5, p.377-387, 1956.

BUENO, A.A. Características estruturais do dossel forrageiro, valor nutritivo e produção de forragem em pastos de capim Mombaça submetidos a regime de lotação intermitente. Piracicaba: Escola Superior de Agricultura Luiz de Queiroz, 2003. 124p. Dissertação (Mestrado em Agronomia) - Escola Superior de Agricultura Luiz de Queiroz, 2003.

CÂNDIDO, M.J.D.; ALEXANDRINO, E.; GOMIDE, J.A. Duração do período de descanso e crescimento do dossel de Panicum maxium cv. Mombaça sob lotação intermitente. Revista Brasileira de Zootecnia, v.34, n.2, p.398-405, 2005a.

CÂNDIDO, M.J.D.; GOMIDE, C.A.M.; ALEXANDRINO, E. et al. Morfofisiologia do dossel de Panicum maximum cv Mombaça sob lotação intermitente com três períodos de descanso. Revista Brasileira de Zootecnia, v.34, n.2, p.406-415, 2005b.

CÂNDIDO, M.J.D.; ALEXANDRINO, E.; GOMIDE, C.A.M. et al. Período de descanso, valor nutritivo e desempenho animal em pastagem de Panicum maximum cv Mombaça sob lotação intermitente. Revista Brasileira de Zootecnia, v.34, n.5, p.1449-1458, 2005c.

DAVIES, A.; EVANS, M.E.; EXLEY, J.K. Regrowth of perennial ryegrass as affected by simulated leaf sheaths. Journal Agricultural Science, v.101, p.131-137, 1983. 
EMPRESA BRASILEIRA DE PESQUISA AGROPECUÁRIA EMBRAPA. Sistema Brasileiro de Classificação de solos. $6^{\text {a }}$ impressão. Brasília: 1999. 412p.

FULKERSON, W.J.; DONAGHY, D.J. Plant soluble carbohydrate reserves and senescence - Key criteria for developing an effective grazing management system for ryegrass based pastures: a review. Australian Journal of Experimental Agriculture, v.41, n.2, p.261-275, 2001.

FULKERSON, W.J.; SLACK, K. Leaf number as a criterion for determining defoliation time for Lolium perenne. 1 - Effect of water-soluble carbohydrate and senescence. Grass and Forage Science, v.49, n.4, p.373-377, 1994.

GOMIDE, C.A.M.; GOMIDE, J.A. Análise de crescimento de cultivares de Panicum maximum Jacq. Revista Brasileira de Zootecnia, v.28, n.4, p.675-680, 1999.

HODGSON, J. Grazing management: science into practice. Harlow: Longman Scientific \& Technical, 1990. 203p.

KORTE, C.J.; WATKINS, B.R.; HARRIS, W. Use of residual leaf area index and light interception as a criteria for spring grazing management of ryegrass dominant pasture. New Zealand Journal of Agricultural Research, v.25, n.3, p.309-319, 1982.

LANGER, R.H.M. Tillering in herbage grasses. Herbage Abstracts, v.33, n.3, p.141-148, 1963.

LEMAIRE, G. Ecophysiology of grasslands: dynamic aspects of forage plant populations in grazed swards. In: INTERNATIONAL GRASSLAND CONGRESS, 19., 2001, São Pedro. Proceedings... Piracicaba: Fundação de Estudos Agrários Luiz de Queiroz, 2001. (CD-ROM).

MELLO, A.C.L. Respostas morfofisiológicas do capim Tanzânia (Panicum maximum, Jacq. cv. Tanzânia) irrigado à intensidade de desfolha sob lotação rotacionada. Piracicaba: Escola Superior de Agricultura Luiz de Queiroz, 2002. 67p. Tese (Doutorado em Agronomia) - Escola Superior de Agricultura Luiz de Queiroz, 2002.

NABINGER, C. Manejo da desfolha. In: SIMPÓsio SOBRE MANEJO DE PASTAGEM: Inovações tecnológicas no manejo de pastagens, 19., 2002, Piracicaba. Anais... Piracicaba: Fundação de Estudos Agrários Luiz de Queiroz, 2002. p.133-158.

NABINGER, C.; PONTES, L.S. Morfogênese de plantas forrageiras e estrutura do pasto. In: REUNIÃO DA SOCIEDADE BRASILEIRA DE ZOOTECNIA, 38., 2001, Piracicaba. Anais... Piracicaba: Sociedade Brasileira de Zootecnia, 2001. p.755-771.

PARSONS, A.J.; LEAFE, E.L.; COLLETT, B. et al. The physiology of grass production under grazing. 2. Photosynthesis, crop growth and animal intake of continuously grazed sward. Journal of Applied Ecology, v.20, n.1, p.127-139, 1983.
PENATI, M.A. Estudo do desempenho animal e produção do capim Tanzânia (Panicum maximum, Jacq.) em um sistema rotacionado de pastejo sob irrigação em três níveis de resíduo pós-pastejo. Piracicaba: Escola Superior de Agricultura Luiz de Queiroz, 2002. 114p. Tese (Doutorado em Agronomia) - Escola Superior de Agricultura Luiz de Queiroz, 2002.

RODRIGUES, L.R.A.; REIS, R.A. Bases para o estabelecimento do manejo de capins do gênero Panicum. In: SIMPÓSIO SOBRE MANEJO DA PASTAGEM: O CAPIMCOLONIÃO, 12., 1995, Piracicaba. Anais... Piracicaba: Fundação de Estudos Agrários Luiz de Queiroz, 1995. p.197-218.

SANTOS, P.M.; BALSALOBRE, M.A.A.; CORSI, M. Uso do número de folhas por perfilho no manejo de Panicum maximum cvs. Mombaça e Tanzânia. In: REUNIÃO DA SOCIEDADE BRASILEIRA DE ZOOTECNIA, 36., 1999, Porto Alegre. Anais... Porto Alegre: Sociedade Brasileira de Zootecnia, 1999. (CD-ROM).

STATISTICAL ANALYSIS SYSTEM - SAS. SAS system for windows. Version 8.0. Cary: 1999. (CD-ROM).

SBRISSIA, A.F.; SILVA, S.C. O ecossistema de pastagens e a produção animal. In: REUNIÃO DA SOCIEDADE BRASILEIRA DE ZOOTECNIA, 38., 2001, Piracicaba. Anais... Piracicaba: Sociedade Brasileira de Zootecnia, 2001. p.731-754.

STOBBS, T.H. The effect of plant structure on the intake of tropical pastures. II. Differences in sward structure, nutritive value, and bite size of animals grazing Setaria anceps and Chloris gayana at various stages of growth. Australian Journal of Agricultural Research, v.24, n.6, p.821-829, 1973.

TAIZ, L.; ZEIGER, E. Fisiologia vegetal. 3.ed. Porto Alegre: Artmed, 2004. p.719.

TEIXEIRA, E.I.; MATTOS, W.R.S.; CAMARGO, A.C. et al. Avaliação de produção e utilização de uma pastagem de capim Tobiatã (Panicum maximum Jacq. cv. Tobiatã) sob pastejo rotacionado. Science Agricultural, v.56, n.2, 1999.

UEBELE, M.C. Padrões demográficos de perfilhamento e produção de forragem em pastos de capim Mombaça submetidos a regimes de lotação intermitente. Piracicaba: Escola Superior de Agricultura Luiz de Queiroz, 2002. 83p. Dissertação (Mestrado em Agronomia) - Escola Superior de Agricultura Luiz de Queiroz, 2002.
Recebido: 19/12/2005 Aprovado: 26/3/2007 